\title{
Validation of Capsaicin in Indian Capsicum Species Through RP-HPLC
}

\author{
Mrinmoy Nag', Joydeb Chanda', Rajarshi Biswas', Naif Abdullah Al-Dhabi², V. Duraipandiyan², Pratim \\ Banerji $^{3}$ and Pulok K. Mukherjee ${ }^{1 *}$
}

1School of Natural Product Studies, Department of Pharmaceutical Technology, Jadavpur University, Kolkata-700032, INDIA. 2Department of Botany and Microbiology, Addiriyah Chair for Environmental Studies, College of Science, King Saud University, Riyadh-11451, SAUDI ARABIA.

${ }^{3}$ Ulysses Research Foundation, 125, Rashbehari Avenue, Kolkata 700029, West Bengal, INDIA.

\begin{abstract}
Capsaicin is a pungent capsacinoid which differs in capsicum fruit within the species and the cultivars due to its topographical diversity. Here, a comparative estimation of capsaicin in seven varieties of capsicum has been performed by RP-HPLC method. The method was carried out in reverse phase $\mathrm{C}_{18}$ column using acetonitrile and water $(1 \%$ acetic acid) as mobile phase $(65: 35 \mathrm{v} / \mathrm{v})$, at the flow rate of $1 \mathrm{ml} / \mathrm{min}$. The $\lambda \max$ was detected at $230 \mathrm{~nm}$. The calibration curves were linear in the concentration range of $1-80 \mu \mathrm{g} / \mathrm{ml}$. The comparative study revealed that the capsaicin content was highest $(3.12 \% \mathrm{w} / \mathrm{w})$ in Capsicum annuum Cayenne whereas Capsicum cardenasii contains the lowest $(0.85 \% \mathrm{w} / \mathrm{w})$. The $\%$ RSD of precision and recovery was found to be $<2 \%$, which confirms high repeatability of the method. This method can be commercialized at industrial level for ensuring the highest quality of capsicum used as raw material.
\end{abstract}

Key words: Ayurveda, Capsaicin, RP-HPLC, Method validation, Capsicum.

\section{INTRODUCTION}

The ripe fruits of capsicum have been used as spices for a long time throughout the world, particularly in India and other tropical countries. It is extensively used in food industry as natural flavoring and coloring agent due to its unique pungency, aroma and color. ${ }^{1}$ Capsicum has several therapeutic properties as topical analgesic, tonic, antiseptic, carminative and counters irritant property and also used for the treatment of rheumatism, arthritis, neuralgia, itching, lumbago and spasms. ${ }^{2}$ It has also some diverse therapeutic application in inflammation, obesity, cardiovascular diseases, gastrointestinal disease, etc. In Mayan medicine capsicum is used for the treatment of bacterial and fungal infection. ${ }^{3}$ Capsicum fruit contains various health-promoting metabolites, such as carotenoids, ascorbic acid (vitamin C), vitamin A and capsaicinoids. ${ }^{4}$ The genus capsicum belongs to
Family- Solanaceae and it consists of more than 30 species. $^{2}$ Among them only five are cultivated in India, including Capsicum annum Cayenne, Capsicum annum Super Shepherd, Capsicum annum Jumbo Jalapeno, Capsicum cardenasii, Capsicum chinense, Capsicum frutescens and Capsicum chacoense. The species and varieties include many economically important cultivars with different shapes, colors and flavors. The morphological and geographical heterogeneity impart in the variation of secondary metabolite contents also in their therapeutic benefits as well as pungency. The major active secondary metabolite found in capsicum species and cultivars is capsaicin. Chemically, it is a decylenic acid amide of vanillyl-amine where the acid portion of the molecule determines its degree of pungency. Now a day, an injectable preparation of capsaicin (Adlea) is used in the treatment of osteoarthritis pain
Submission Date: 30-08-2016; Revision Date: 17-11-2016; Accepted Date: 02-02-2017

DOI: $10.5530 / \mathrm{ijper.51.2.40}$ Correspondence: Dr. Pulok K. Mukherjee, Director, School of Natural Product Studies, Dept. of Pharmaceutical Technology, Jadavpur University, Kolkata 700032, INDIA.

Phone no: +9133 24298313

E-mail: naturalproductm@ gmail.com

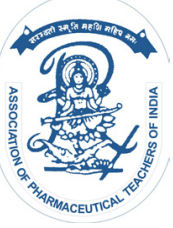

www.ijper.org 
and neuropathic pain. ${ }^{5}$ Capsaicin is also used to induce cell-cycle arrest or apoptosis or inhibit cell proliferation in a variety of cancer cells. ${ }^{6}$ Some capsaicin containing creams are used for the treatment of painful conditions such as long-term neuropathic pain in cancer patients ${ }^{7}$ and diabetic neuropathy. ${ }^{8}$

The quantity of active compounds depends on several factors such as intra species variability, environmental conditions, geographical variations, harvesting and storage time and extraction methods. ${ }^{9}$ Marker profiling and standardization of medicinal plants can help in finding an optimum concentration of bioactive compounds present in herbal drugs and thus ensures it quality. ${ }^{10}$ In this context, proper quantitative evaluation of capsaicin in various types of capsicum is necessary to evaluate its content uniformity that can ensure its commercial quality. However, the lack of chemical markers remains a major problem in this context. ${ }^{11}$ In 2012, Gantait et al. ${ }^{12}$ reported a validated HPTLC method for quantification of capsaicin in different varieties of capsicum found in India. ${ }^{12}$ HPLC is one of the convenient and comprehensive technique for separating the individual components in plant extracts which has great importance in relation to their authentication, fingerprinting, quantification, quality control in herbal industry, ${ }^{13}$ so we aimed to perform a comparative estimation of capsaicin through High Performance Liquid Chromatography (HPLC) in seven varieties of capsicum collected from different region of India. This information will be helpful to identify the best capsicum variety (higher yield, higher capsaicin content) as raw material of capsaicin used in industrial as well as therapeutic purpose.

\section{MATERIAL AND METHODS}

\section{Chemicals and reagents}

Methanol and glacial acetic acid (HPLC grade) were procured from Merck (Mumbai, India). All other solvents used were of analytical grade, procured from Merck. Capsaicin was purchased from Sigma Aldrich (St. Louis, MO, USA).

\section{Instrumentation}

The HPLC system (Waters, Milford, MA, USA) used for the analysis was consisted of a 600 controller pump, a multiple-wavelength ultraviolet-visible (UV-Vis) detector equipped with an in-line degasser AF 2489 and a rheodyne $7725 i$ injector having $20 \mu \mathrm{L}$ loop. Quantitative estimation was performed with Empower 2 software programs using the external calibration method. A Milli-Q
Academic water purification system (Bedford, MA, USA) equipped with $0.22 \mathrm{~mm}$ Millipak Express filter and Eyela (Tokyo, Japan) rotary vacuum evaporate were used. Membrane filters of $0.45 \mu \mathrm{m}$ pore size (Millipore) were used for filtration of the mobile phase and syringe filters (NYL $0.45 \mu \mathrm{m}$ ) were used for the filtration of the sample solution.

\section{Extraction of plant material}

All seven varieties of capsicum were collected from different parts of West Bengal, India as mentioned in Table 1. They were authenticated and the voucher specimen of all of them has been retained in the School of Natural Product Studies, Jadavpur University, Kolkata vide voucher specimen number SNPS-1462 for future references. The materials were shade dried and powdered. 40 grams of each of powdered material ware extracted with methanol by cold maceration for 72 hours. Finally, the material was filtered and the filtrates of each variety were taken and concentrated under vacuum using a rotary evaporator and was dried completely to a constant weight. The percentage yield of the extract of each variety of capsicum was calculated (Table 2).

\section{Preparation of standard and sample solution}

About $10 \mathrm{mg}$ of capsaicin standard was weighed and taken in $10 \mathrm{ml}$ volumetric flask. Then $5 \mathrm{ml}$ methanol was added in the flask, mix thoroughly and sonicated for $5 \mathrm{~min}$. The volume was made up to $10 \mathrm{ml}$ with methanol. The sample solutions were prepared by taking $10 \mathrm{mg}$ of extract in $1 \mathrm{ml}$ methanol. The solution was filtered through $0.45 \mu \mathrm{l}$ syringe filter prior to injection. The linearity of the response prepared standards was determined using a calibration curve established with five dilutions of standard, at concentrations ranging from 1 to $80 \mu \mathrm{g} / \mathrm{ml}$. The corresponding peak areas of the standards were plotted against the concentration of each standard.

\section{Method validation}

Method validation was executed by linearity, specificity, accuracy and precision, limit of quantification and limit of detection on the basis of International Conference on Harmonization ( $\mathrm{ICH}$ ) guidelines. ${ }^{14}$

Method specificity was determined by comparing the retention time of both standard and test samples. This mainly ensures the identity and purity of the analyte and to minimize the error due to the contamination of the sample.

Sensitivity was evaluated by determining the Limit of Detection (LOD) and Limit of Quantification (LOQ) and calculated based on the $\mathrm{ICH}$ guideline by determining 


\begin{tabular}{|c|c|c|c|}
\hline \multicolumn{4}{|c|}{ Table 1: Different capsicum species used for analysis } \\
\hline Local Name & English Name & Geographical Location & Scientific Name \\
\hline Acchar Lanka & Pepperoncini & Kolkata in West Bengal & Capsicum annum Super Shepherd \\
\hline Bullet Lanka & Jalapeno pepper & Kolkata in West Bengal & Capsicum annum Jumbo Jalapeno \\
\hline Commercial Lanka & Cayenne pepper & Kolkata in West Bengal & Capsicum annuum Cayenne \\
\hline Kul Lanka & Cherry pepper & Kolkata in West Bengal & Capsicum cardenasii Heiser and P.G.Sm. \\
\hline Dhani Lanka & Birds eye & Kolkata in West Bengal & Capsicum chacoense Hunz. \\
\hline Dalle Khorsani & Habanero chilli & Darjeeling in West Bengal and Sikkim & Capsicum chinense Jacq. \\
\hline Akashi/kalojm Lonka & Bolivian rainbow & Coochbehar in West Bengal & Capsicum frutisence L. \\
\hline
\end{tabular}

\begin{tabular}{|c|c|c|}
\hline \multicolumn{2}{|c|}{ Table 2: Content of capsaicin in different varieties of capsicum species } \\
\hline Variety of Capsicum Species & $\begin{array}{c}\text { Percentage Yield of Extract } \\
(\% \mathbf{w} / \mathbf{w})\end{array}$ & $\begin{array}{c}\text { Capsaicin Content in Extract } \\
(\% \mathbf{w} / \mathbf{w})\end{array}$ \\
\hline Capsicum annuum Cayenne & 18.40 & 3.12 \\
\hline Capsicum annum Super Shepherd & 16.12 & 2.58 \\
\hline Capsicum annum Jumbo Jalapeno & 15.84 & 2.44 \\
\hline Capsicum cardenasii & 10.18 & 0.85 \\
\hline Capsicum chacoense & 13.77 & 1.97 \\
\hline Capsicum chinense & 15.26 & 2.31 \\
\hline Capsicum frutisence & 11.52 & 1.25 \\
\hline
\end{tabular}

Table 3: Intra-day and inter-day precision of HPLC method

\begin{tabular}{|c|c|c|c|c|c|c|c|}
\hline \multicolumn{7}{|c|}{ Capsaicin } \\
\hline \multicolumn{3}{|c|}{ Intra-day (n=6) } & \multicolumn{4}{c|}{ Inter-day (n=6) } \\
\hline \multicolumn{2}{|c|}{ RT (min) } & \multicolumn{2}{|c|}{ Response (AU) } & \multicolumn{2}{c|}{ RT (min) } & \multicolumn{2}{c|}{ Response (AU) } \\
\hline Mean & \% RSD & Mean & \% RSD & Mean & \% RSD & Mean & $\%$ RSD \\
\hline 5.17 & 0.87 & 571071.7 & 1.20 & 5.14 & 1.50 & 567840.7 & 1.28 \\
5.16 & 1.47 & 223700.0 & 1.30 & 5.17 & 1.17 & 224405.0 & 1.81 \\
5.13 & 1.46 & 440735.9 & 1.25 & 5.14 & 1.10 & 445300.1 & 1.50 \\
\hline
\end{tabular}

\section{Table 4: Recovery studies for determination of capsaicin in ethanol extract of capsicum species}

\begin{tabular}{|c|c|c|c|c|c|}
\hline Biomarker & $\begin{array}{c}\text { Amount } \\
\text { Added }\end{array}$ & $\begin{array}{c}\text { Sample } \\
\text { Concentration }(\mu \mathrm{g} / \\
\mathrm{ml})\end{array}$ & $\begin{array}{c}\text { Theoretical } \\
\text { Concentration }(\mu \mathrm{g} / \\
\mathrm{ml})\end{array}$ & $\begin{array}{c}\text { Actual } \\
\text { Concentration }(\mu \mathrm{g} / \\
\mathrm{ml})\end{array}$ & $\begin{array}{c}\text { Percentage } \\
\text { Recovery }\end{array}$ \\
\hline Capsaicin & $\begin{array}{l}10 \\
40 \\
80\end{array}$ & $\begin{array}{l}1428.6 \\
1428.6 \\
1428.6\end{array}$ & $\begin{array}{l}1438.6 \\
1468.6 \\
1508.6\end{array}$ & $\begin{array}{c}1340.96 \\
1390.3 \\
1480.3\end{array}$ & $\begin{array}{l}95.99 \\
96.82 \\
98.87\end{array}$ \\
\hline
\end{tabular}

the $\mathrm{SD}$ of the response and the slope of the linear equation. The LOD and LOQ were calculated by the equation: $\mathrm{LOD}=3.3 \sigma / \mathrm{S}$ and $\mathrm{LOQ}=10 \sigma / \mathrm{S}$, where $\sigma$ is the standard deviation and $\mathrm{S}$ is the slope of the calibration curve.

Intra-day and inter-day assay accuracy and precision for each analyte were determined at LQC (low quality control), MQC (medium quality control) and HQC (high quality control). Both the parameters were assessed by comparing data from within one run $(n=6)$. Accuracy of the method was determined by standard addition technique and expressed in terms of $\%$ relative standard deviation ( $\%$ RSD) for mean recovery of the theoretical concentration. The samples were spiked with three different amounts of standard compounds in triplicate and analyzed under the previously established optimal condition. The precision of the analytical method was assessed by injecting six replicates at three different concentrations of the reference compounds. The values were represented as \% RSD of intra-day and inter-day analysis. System suitability testing was performed by using six replicates of test concentrations. Variations in number of theoretical plates, capacity 
factor, and tailing factor were calculated as average of six replicates.

Robustness study was performed by changing different mobile phase composition, flow rate and detection of wave length to determine their influence on the retention time. Statistical analysis was performed using the Graph Pad Prism Version 5.0. The result has been represented as the mean $\pm \%$ RSD.

\section{RESULTS}

\section{Chromatographic conditions}

HPLC assays were performed using isocratic conditions by the external standard method. Mobile phase composition was optimized to acetonitrile (solvent $\mathrm{A}$ ) and water (solvent B) in the ratio of $65: 35(\mathrm{v} / \mathrm{v})$. The $\mathrm{pH}$ of the solvent $\mathrm{B}$ was adjusted at 3.8 by using $1 \%(\mathrm{v} / \mathrm{v})$ glacial acetic acid. A reverse phase $\mathrm{C}_{18}$ column $(5 \mu \mathrm{m}$ particle size, $\left.250 \times 4.6^{\prime \prime}\right)$ was used for the separation. The temperature of the column was kept at $25^{\circ} \mathrm{C}$ and injection volume was $20 \mu \mathrm{l}$. The Flow rate was set at $1.0 \mathrm{ml} / \mathrm{min}$ and the absorbance was detected at $230 \mathrm{~nm}$.

\section{Validation parameters}

The linearity of the calibration plot was found to be $1-80 \mu \mathrm{g} / \mathrm{ml}$. The correlation co-efficient was found from the calibration curve as $>0.99$, which confirms that the data is closer to the line of best fit. The regression equation was found to be $\mathrm{Y}=51474 \mathrm{X}+137928$. The high recovery values (95.99-98.87\%) indicated the accuracy of the method (Table 2). The \% RSD of intra-day and inter-day precision was found to be $<2 \%$, which confirms high repeatability of the method (Table 1). After calibration range the limits of detection (LOD) and limit of quantification (LOQ) were estimated to be 148.34 and $445.32 \mathrm{ng} / \mathrm{ml}$ respectively.

The number of theoretical plates, capacity factor and tailing factor were found to be $4092 \pm 1.69$ (desirable > 2000), $6.72 \pm 1.12$ (desirable 2-10), $1.35 \pm 1.48$ (desirable $<1.5$ ), respectively, from the mean of six determinations of test concentration.

\section{Quantification of capsaicin in different capsicum species}

The content was determined by HPLC method using capsaicin as a biomarker (Table 3). The chromatogram of standard capsaicin has been shown in Figure 1a, Chromatogram of different varieties of Capsicum annum have been shown in Figure 2-7, e.g. Capsicum annuum Cayenneextract(Figure1b),Capsicum annumSuperShepherd extract (Figure 2), Capsicum annum Jumbo Jalapeno extract (Figure 3). Chromatogram of Capsicum cardenasii extract (Figure 4), Capsicum chacoense extract (Figure 5), Capsicum cbinense extract(Figure 6), Capsicum frutisence extract (Figure 7) was developed using the mobile phase acetonitrile and $1 \%$ acetic acid in water $(65: 35 \mathrm{v} / \mathrm{v}), \mathrm{C}_{18}$ column through RP-HPLC. The content of the capsaicin in the methanol extract was determined using a calibration curve by plotting the mean peak area ( $y$-axis) against the concentrations ( $x$-axis). Among them Capsicum annum Cayenne (Cayenne pepper) possess highest capsaicin content, whereas Capsicum cardenasii (Cherry pepper) contains the lowest.

\section{DISCUSSION}

The amount of capsaicin present in different varieties of capsicum mainly depends on their different genetic structure, environmental factors, soil characteristics as

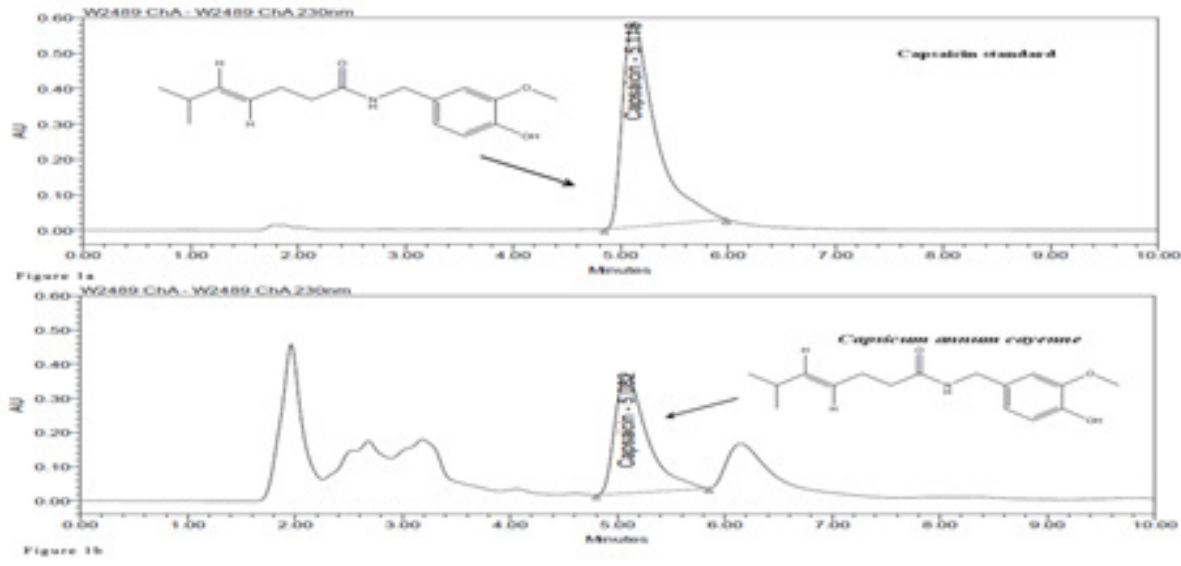

Figure 1a: RP-HPLC chromatogram of capsaicin standard. Figure 1b: RP-HPLC chromatogram of Capsicum annuum Cayenne extract. 


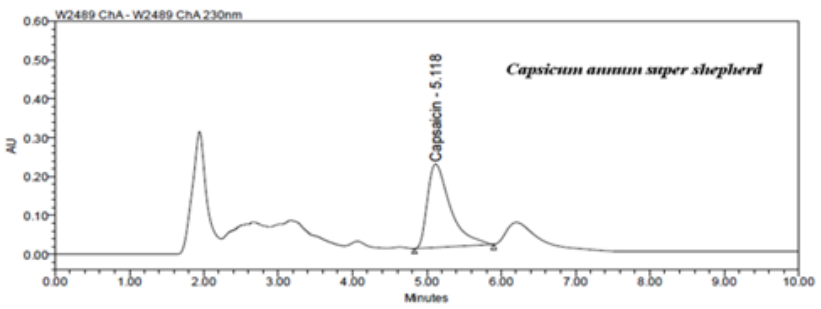

Figure 2: RP-HPLC chromatogram of Capsicum annum Super Shepherd extract.

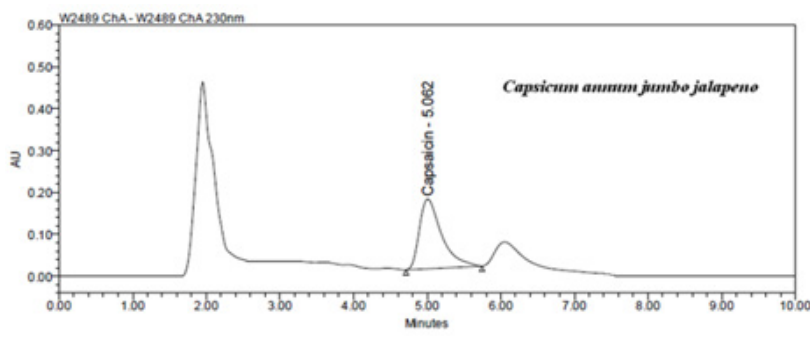

Figure 3: RP-HPLC chromatogram of Capsicum annum Jumbo Jalapeno extract.

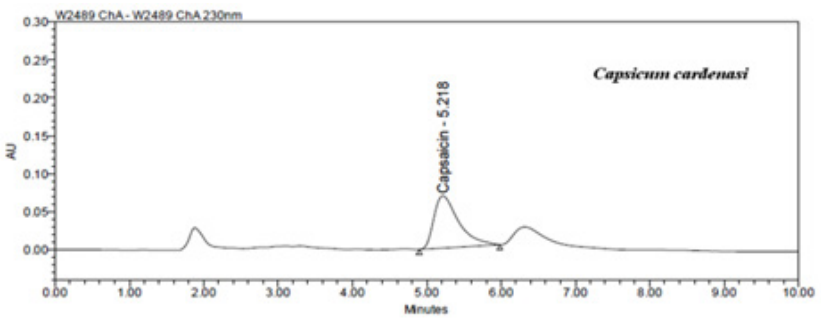

Figure 4: RP-HPLC chromatogram of Capsicum cardenasii extract.

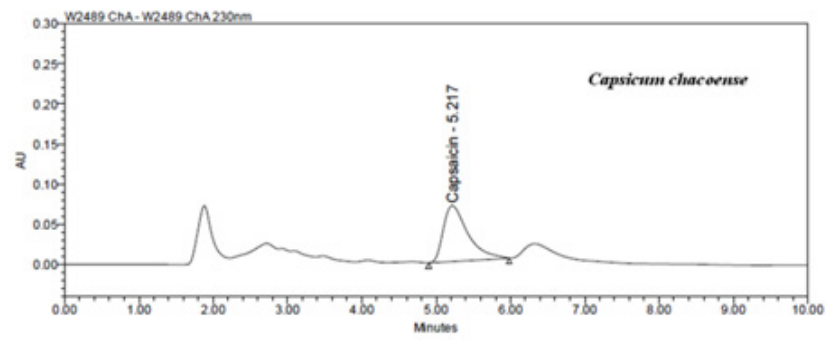

Figure 5: RP-HPLC chromatogram of Capsicum chacoense extract.

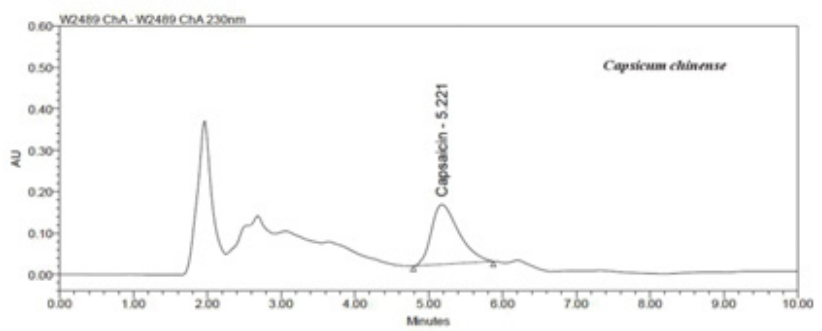

Figure 6: RP-HPLC chromatogram of Capsicum chinense extract.

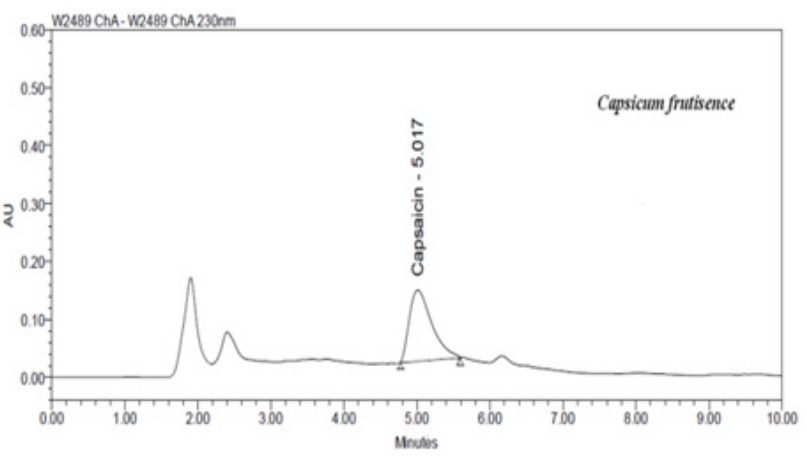

Figure 7: RP-HPLC chromatogram of Capsicum frutisence extract.

well as agricultural practices. ${ }^{15}$ The capsaicin content in different capsicum species and cultivars depends on their morphological parameters like placental tissues, pericarp and seeds. It has been noted that the pericarp contains almost all the pungency and thus determines the quality characters in chillies. ${ }^{2}$ The variation of capsaicin content mainly reflects the quality of various food and pharmaceutical preparation containing capsicum. It has been found that capsaicin content is highest in Capsicum annum Cayanne, which may be due to their morphological character as well as their different soil characteristics. The developed method was very accurate, precise and reproducible with a narrow linear range. Thus, this studied method can be commercialized at industrial level for ensuring the highest quality of capsicum as raw material for food and pharmaceutical preparation.

\section{CONCLUSION}

This study highlights on the estimation of capsaicin in different capsicum based on their geographical occurrences. This study may be useful to evaluate the content of capsaicin level of various types of capsicum fruits as well as its presences in various pharmaceutical and food preparation. Proper quality evaluation also can be performed by this validated method which can ensure the content uniformity of capsaicin in different capsicum.

\section{ACKNOWLEDGEMENT}

The authors are thankful to the Department of Biotechnology, Government of India, New Delhi, India for financial support through Tata Innovation fellowship program to corresponding author.

\section{CONFLICT OF INTEREST}

The authors declare that they have no conflict of interest. 


\section{ABBREVIATIONS USED}

RP-HPLC: Reverse Phase High Performance Liquid Chromatography; RSD: Relative Standard Deviation; HPTLC: High Performance Thin Layer Chromatography; $\mu \mathrm{L}$ : Micro liter; mm: Milli miter; $\mu \mathrm{m}$ : Micro miter; ml: Milli liter; mg: Milli gram; $\mu$ g: Micro gram; ICH: International Conference on Harmonization; LOD: Limit of Detection; LOQ: Limit of Quantification; LQC: Low quality control; MQC: Medium quality control; HQC: High quality control; nm: Nano meter; RT: Retention time.

\section{REFERENCES}

1. Arora R, Gill NS, Chauhan G, Rana AC. An overview about versatile molecule capsaicin. Int J Pharm Sci Drug Res. 2011;5:280-6.

2. Yaldiz G, Ozguven M, Sekeroglu N. Variation in capsaicin contents of different capsicum species and lines by varying drying parameters. Ind Crops Prod. 2010;32(3):434-8. https://doi.org/10.1016/j.indcrop.2010.06.013.

3. Cichewicz RH, Thorpe PA. The antimicrobial properties of chile peppers (capsicum species) and their uses in Mayan medicine. J Ethnopharmacol. 1996;52(2):61-70. https://doi.org/10.1016/0378-8741(96)01384-0.

4. Topuz A, Ozdemir F. Assessment of carotenoids, capsaicinoids and ascorbic acid composition of some selected pepper cultivars (Capsicum annuum L.) grown in Turkey. J Food Compost Anal. 2007;20(7):596-602. https://doi. org/10.1016/j.jfca.2007.03.007.

5. Remadevi RR, Szallisi AA. Adlea (ALGRX-4975), an injectable capsaicin (TRPV1 receptor agonist) formulation for long lasting pain relief. I Drugs. 2008;11(2):120-32. PMid:18240098

6. Bode AM, Dong Z. The two faces of capsaicin. Cancer Res. 2011;71(8):280914. https://doi.org/10.1158/0008-5472.CAN-10-3756 PMid:21487045.

7. Ellison N, Loprinzi CL, Kugler J, Hatfield AK, Miser A, Sloan JA, et al. Phase III placebo-controlled trial of capsaicin cream in the management of surgical

\section{PICTORIAL ABSTRACT}

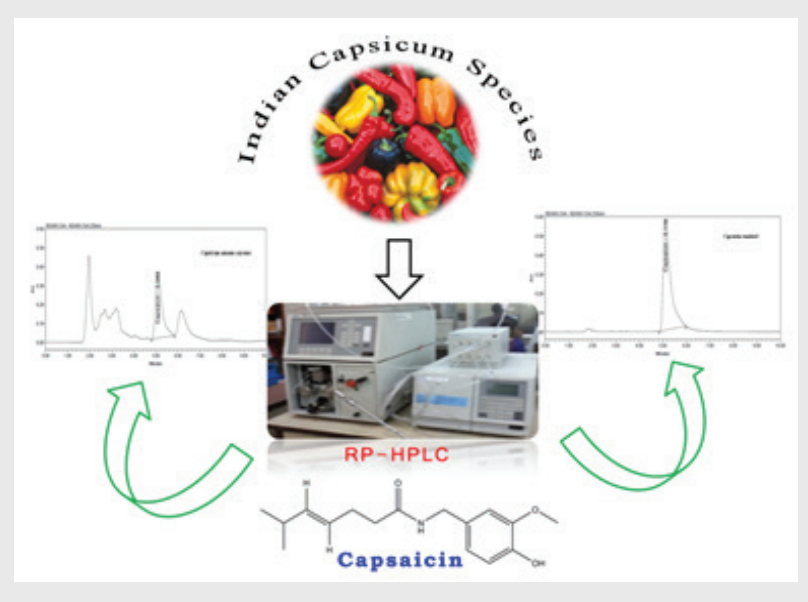

neuropathic pain in cancer patients. J Clin Oncol. 1997:15(8):2974-80. PMid:9256142

8. Hautkappe M, Roizen MF, Toledano A, Roth S, Jeffries JA, Ostermeier AM Review of the effectiveness of capsaicin for painful cutaneous disorders and neural dysfunction. The Clin J Pain. 1998;14(2):97-06. https://doi. org/10.1097/00002508-199806000-00003 PMid:9647450.

9. Lee MK, Ling JH, Chun MH, Jeong JH, Na YC, Lee KW. Simultaneous determination of biological marker compounds in Ostericum koreanum by HPLC method and discrimination by principal component analysis. Bull Korean Chem Soc. 2008;29(12):2465-70. https://doi.org/10.5012/ bkcs.2008.29.12.2465

10. Mukherjee PK, Rai S, Bhattacharya S, Wahile A, Saha BP. Marker analysis of polyherbal formulation, triphala-a well known Indian traditional medicine. Indian J Tradit Know. 2008;7(3):379-83.

11. Mukherjee PK, Bahadur S, Chaudhary SK, Kar A, Mukherjee K. Quality related safety issue-evidence-based validation of herbal medicine farm to pharma. In: Mukherjee PK, editor. Evidence-based validation of herbal medicine. Amsterdam: Elsevier science. 2015;1-28. https://doi.org/10.1016/ B978-0-12-800874-4.00001-5.

12. Gantait A, Maji A, Barman T, Banerji P, Venkates P, Mukherjee PK. Estimation of capsaicin through scanning densitometry and evaluation of different varieties of capsicum in India. Nat Prod Res. 2012;26(3):216-22. https://doi. org/10.1080/14786419.2010.535169 PMid:21834628.

13. Mukherjee PK. Quality Control on Herbal Drugs. 1st ed. New Delhi: Business Horizons; 2002.

14. $\mathrm{ICH}, \mathrm{Q} 2(\mathrm{R} 1)$. Validation of analytical procedure: Methodology, International Conference of Harmonization for Technical requirements for the Registration of Drug for Human use, Geneva, Switzerland. 2005.

15. Jarret RL, Levy IJ, Potter TL; Cermak SC. Seed oil and fatty acid composition in capsicum spp. J Food Compos Ana. 2013;30(2):102-8. https://doi. org/10.1016/j.jfca.2013.02.005.

\section{SUMMARY}

- A validated method for estimation of capsaicin in Indian capsicum species through RP-HPLC.

- Acetonitrile and water (1\% acetic acid) used as mobile phase in the ratio of $65: 35 \mathrm{v} / \mathrm{v}$, with flow rate of $1 \mathrm{ml} / \mathrm{min}$.

- The retention time of capsaicin was found to be $5.118 \pm 0.1$ minute in different capsicum species.

- The method was validated as per International Conference on Harmonization (ICH) guidelines.

- All validation parameters were found to be within the limit.

- This method can be commercialized at industrial level for ensuring the highest quality of capsicum used as raw material.

Cite this article: Nag M,Chanda J, Biswas R, Al-Dhabi NA, Duraipandiyan V, Banerji P, Mukherjee PK. Validation of capsaicin in Indian capsicum species through RP-HPLC. Indian J of Pharmaceutical Education and Research. 2017;51(2):337-42. 